\title{
GÜNEYDOĞU ANADOLU BÖLGESİNDEKİ İLLERIN KURAKLIK ANALİZİ
}

\author{
1Türker TUĞRUL, ${ }^{2}$ Selim DOĞAN, ${ }^{3 S}$ Sükrü DURSUN \\ ${ }^{1}$ Kırşehir Ahi Evran Üniversitesi, Rektörlük, Kırşehir, TÜRKIYE \\ ${ }^{2,3}$ Konya Teknik Üniversitesi, Mühendislik ve Doğa Bilimleri Fakültesi, Çevre Mühendisliği Bölümü, Konya, \\ TÜRKIYY \\ 1turkertugrul@ahievran.edu.tr, ${ }^{2}$ sdogan@ktun.edu.tr, ${ }^{3}$ sdursun@ktun.edu.tr
}

(Geliş/Received: 17.07.2017; Kabul/Accepted in Revised Form: 26.03.2019)

\begin{abstract}
ÖZ: Bu çalışmada Güneydoğu Anadolu Bölgesindeki illerin kuraklık analizi yapılmıştır. Çalışmada 9 istasyondan alınan 1960-2016 yılları arasındaki aylık toplam yağış verileri kullanılmıştır. Analiz için en az 30 senelik kesintisiz veri setine ihtiyaç duyulmaktadır. Bu koşul Şırnak istasyonunda sağlanamamıştır. Analizde Efektif Kuraklık İndeksi (EKİ) yönteminden yararlanılmıştır. Çalışma sonucunda Adiyaman istasyonunda 22, Batman istasyonunda 15, Diyarbakır istasyonunda 24, Gaziantep istasyonunda 25, Kilis istasyonunda 20, Mardin istasyonunda 9, Siirt istasyonunda 18, Şanlıurfa istasyonunda 21 olmak üzere toplamda 154 kuraklık olayı tespit edilmiştir. 1970-1979 dönemi kuraklık olaylarının en fazla yaşandığı dönemdir. Analiz yapılan 681 aylık zaman periyodu göz önüne alındığında; bu periyotta tüm zamanların ortalama \%19'luk zaman diliminin bölgeyi etkileyen kuraklıklarla geçtiği belirlenmiştir.
\end{abstract}

Anahtar Kelimeler: Kuraklık İndeksi, Yağış, Kuraklık, Efektif kuraklık indeksi (EKI)

\section{Drought Analysis of Provinces in Southeastern Anatolia Region}

\begin{abstract}
In this study, the drought analysis of Southeastern Anatolia Region was conducted. Monthly total rainfall data of1960-2016 taken from 9 stations were used in the paper. At least 30 years of continuous data set is needed for the analysis. This requirement was not met for Sirnak station. For the analysis, the Effective Drought Index (EDI) method was used. As a result of this study, in Adiyaman 22; Batman 15; Diyarbakir 24; Gaziantep 25; Kilis 20; Mardin 9; Siirt 18; Sanliurfa 21,total of 154drought events were detected. The period of 1970-1979 was the period in which drought events were experiencedthe most. Droughts were detected for $19 \%$ out of all times which was 681-month.
\end{abstract}

Key Words: Drought Index, Rainfall, Drought, Effective Drought Index (EDI)

\section{GİRIŞ (INTRODUCTION)}

Kuraklık insanlık için tehlikeli doğal felaketler arasında yer alır. Çevre ve ekonomik olarak en yıkıcı olanıdır. Son zamanlarda iklim değişikliği ile kendisini iyice hissettirmektedir(Tsakiris ve diğ., 2007). Kuraklık hakkında birçok tanım yapılmıştır. Bazı tanımlara göre belirli tarihlerdeki yağış eksikliği, bazılarına göre ise uzun zaman boyunca yağışların olmamasıdır(Byun ve Wilhite, 1999). Kuraklık tanımlarından biriside; belirli bir zaman dilimindeki ortalama yağış miktarındaki azalmadır(Doğan, 2013).

Kuraklık ilk başladığında fark edilmeyebilir. Kuraklık hakkında bilgi sahibi olabilmemiz için istatiksel metotlar (kuraklık indeksleri) geliştirilmiştir. Bu istatiksel metotlarla kuraklığın sınıfı, şiddeti, keskinliği, başlangıç ve bitiş süresi, hatta matematiksel modeller yardımıyla ileriye yönelik tahminler 
bile yapılabilir. Kuraklık indeksi belirlemede onlarca metot türetilmiştir(Lee ve diğ., 2012). Standart Yağış İndeksi (SYİ), Efektif Kuraklık İndeksi (EKİ), Z-skoru, Palmer Kuraklık İndeksi bunlardan bazılarıdır.

\section{ÇALIŞMA ALANI (STUDY AREA)}

Türkiye'de kuraklığa yol açan temel faktörler arasında; atmosferik ve topoğrafik koşulların (yükselti, bakı, eğim vb.) rolü öne çıkmaktadır. Mevsimlik kuraklık söz konusu olduğunda Güneydoğu Anadolu ve İç Anadolu bölgeleri önde gelen bölgeler arasında yerini korurken Doğu Anadolu'da da son yıllarda hissedilir derecede yağış azalmasına bağlı mevsimlik kuraklık eğilimi dikkat çekmektedir (Çelik ve diğ., 2018).

Türkiye farklı coğrafi bölgelerden oluşmaktadır. Güneydoğu Anadolu Bölgesi'nde su varlığının önemi bir hayli fazladır. Dolayısıyla bu bölgede su ile ilgili birçok çalışma, plan ve proje yapılmış ya da yapılmaktadır. Bu nedenle bu makalede çalışma alanı olarak Güneydoğu Anadolu Bölgesi seçilmiştir. Güneydoğu Anadolu Bölgesi Türkiye'yi oluşturan yedi coğrafi bölgeden en küçüğüdür. Suriye'nin kuzeyinden, Güneydoğu Toroslarının güneyine kadar olan alanı kapsamaktadır. Kuzeyinde Doğu Anadolu, Batısında Akdeniz Bölgesi yer almakla birlikte, çoğunluğunu Suriye ile oluşturduğu bir sınır bölgesidir (Şekil 1). Bu bölge ülkemizin en düzlük bölgelerinden birisidir. Hint Okyanusu'na kadar bu düzlük gitmektedir (Hınıs, 2013).

Bölge'nin yüzölçümü 75,6 km² olup, 2015 yılı adrese dayılı nüfus tespitine göre nüfusu yaklaşık olarak 8 milyondur. Ülke topraklarının \%9,7'si, nüfusun da \%9,8'i bu bölgede bulunmaktadır. Hem ülke genelinde hem de bölgede $\mathrm{km}^{2}$ başına 81 kişi düşmektedir. Ortalama yıllık nüfus artış hızı Bölge'de $\% 2,4$, ülke genelinde ise \%1,5 olup, Bölge'nin yıllık nüfus artış hızı ülke ortalamasından yüksektir.
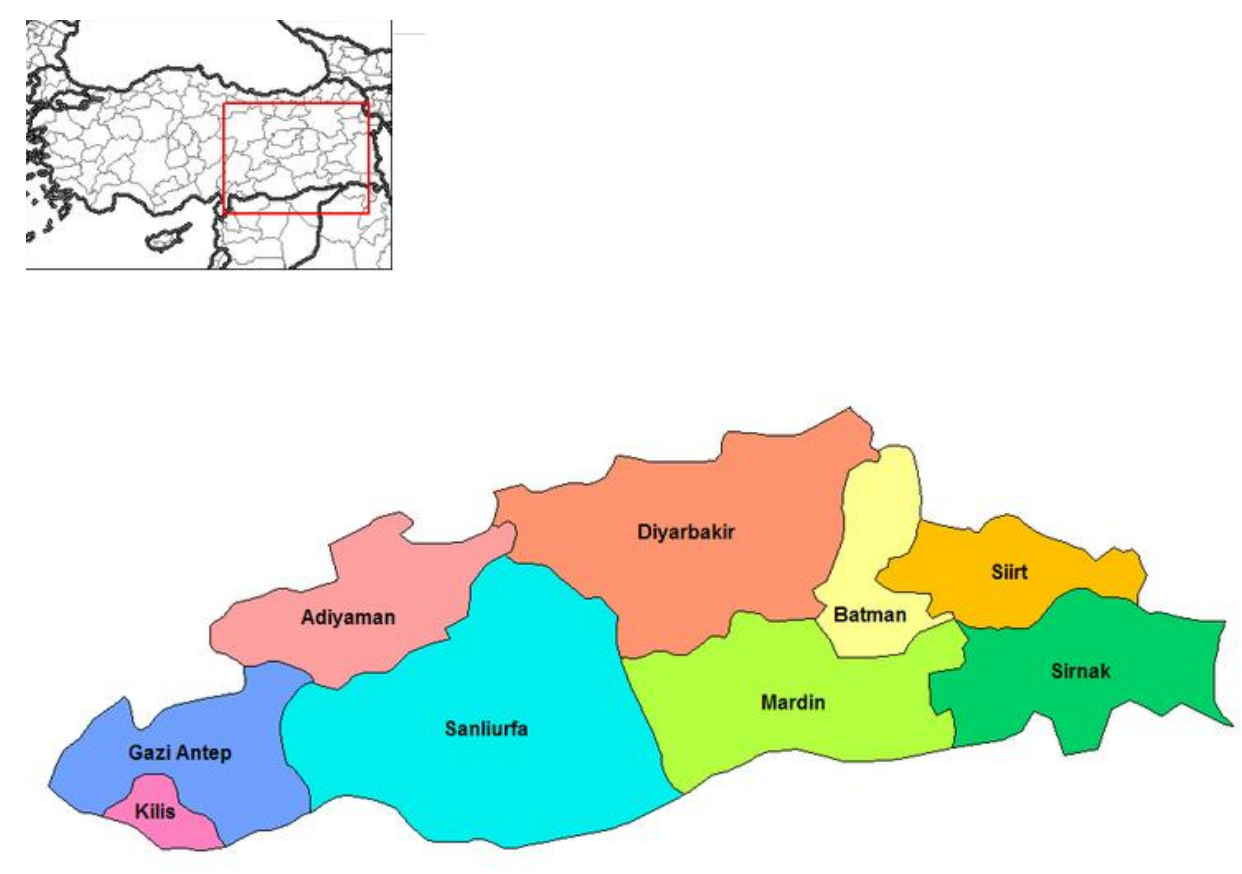

Şekil 1. Güneydoğu Anadolu Bölgesi

Figure 1. Southeast Anatolia Region 


\section{MATERYAL VE YÖNTEM (MATERIAL AND METHOD)}

Bu çalışmada EKİ yöntemi kullanılmıştır. Bu yöntemin diğer hesaplama yöntemlerine göre üstünlükleri vardır(Byun ve Wilhite, 1999). Çünkü diğer metotlar ile aylık toplam yağış verisine göre hesaplama yapılıyorken, Efektif Kuraklık İndeksi ile hem günlük yağış verisiyle hem de aylık toplam yağış verisiyle hesaplama yapılabilir. Literatürdeki birçok çalışmada da Efektif Kuraklık İndeksi'nin diğer yöntemlere göre korelasyonunun yüksek olduğu vurgulanmıştır(Lee ve diğ., 2015).

$\mathrm{Bu}$ çalışmada kullanılan veriler, Meteoroloji Genel Müdürlüğü'nün online veri tabanından alınmıştır. Toplamda bu bölgede 22 istasyon bulunmaktadır. Bunların 21'i aktif şekilde çalışmaktadır. Bu istasyonlardan elde edilen verilerin bir kısmında eksiklikler vardır. Analizin doğruluğu için en az 30 senelik eksiksiz bir veriye ihtiyaç vardır(Palmer, 1965). Bu kapsamda; il merkezlerindeki istasyonlardan alınan verilerin eksikliklerin daha az olduğu tespit edilmiştir. Sonuç olarak 8 il merkezine ait istasyondan yararlanılmıştır. İstasyon bilgileri Çizelge 1'de gösterilmiştir.

Bu analiz için 9 ile ait istasyonlardan 1960-2016yılları arasındaki aylık toplam yağış verilerinden yararlanılmıştır(Tuğrul, 2017). İl merkezleri istasyonlarından alınan verilerin bir kısmında eksiklikler vardır. Bu eksiklikler istasyonların bakım ya da onarımından kaynaklanabilmektedir. Eksiklikler giderilirken; veri setinde eksiği olan istasyonun komşu istasyonlarından yararlanılmıştır. Örneğin; A istasyonunda Kasım 1975 tarihinin verisi kaydedilmemiş olsun. Eksiği tamamlamak için; A istasyonuna yakın olan en az 3 istasyon belirlenir. Bu istasyonların Kasım 1975 tarihindeki verilerinin aritmetik ortalaması alınır. Böylece verisi eksik A istasyonunun ilgili tarihini temsil edebilecek yakın değer bulunmuş olur.

Şırnak istasyonuna ait verilerin büyük bir çoğunluğunda eksiklikler göze çarpmıştır. Bu istasyonun verileri tamamlanmamış analiz dışında tutulmuştur.

Çizelge 1. GAP illerine ait istasyonların bilgileri

Table 1. Information on stations located in the Southeastern Anatolia Region

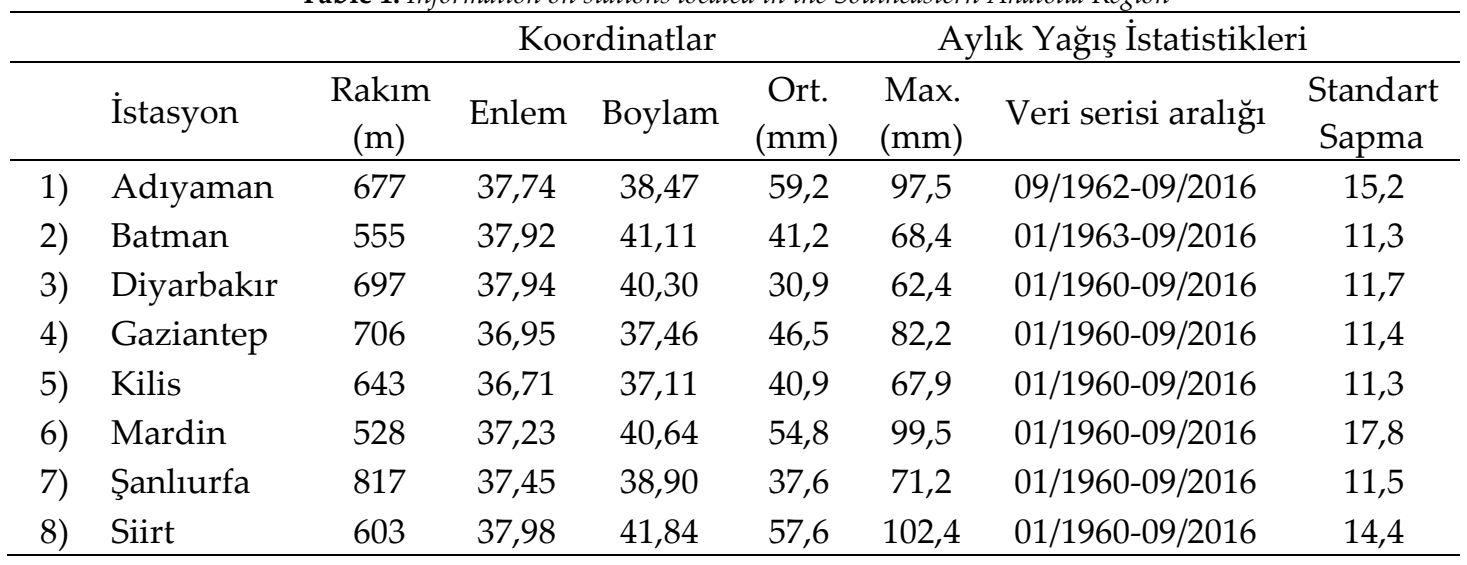

\section{EFEKTİF KURAKLIK İNDEKSİ (EFFECTIVE DROUGHT INDEX)}

EKİ kuraklık karakterizasyonu için kullanılır ve normale dönüş yağışının (NDY) bir fonksiyonudur. Aylık Efektif yağışlar (EY) kullanılarak NDY hesaplanır. İlk başta Denklem (1)'de gösterildiği gibi EY hesaplanır. Buradaki $P_{i}$ aylık yağış miktarı $(\mathrm{mm}), N$ hesaplanacak olan ayların süresidir.

$$
E Y=\sum_{k=0}^{N}\left[\left(\sum_{i=0}^{m} P i / m\right)\right](1)
$$

Bir sonraki adımda ise EY'nin ortalaması (EYo) bulunur. EY'nin ortalamadan sapması (EYS), Denklem (2) ile hesaplanır. NDY değeri ise Denklem (3) ile hesaplanır. En son adımda ise EKİ değeri NDY'nin standart sapması olan $\sigma N D Y$ değerine bölünerek bulunur Denklem (4). 


$$
\begin{aligned}
& E Y S=E Y-E Y o(2) \\
& N Y D=\frac{E Y S}{\sum_{i=2}^{N} \frac{1}{\bar{i}}}(3) \\
& E K \dot{\mathrm{I}}=N D Y / \sigma N D Y(4)
\end{aligned}
$$

Elde edilen EKİ değerleri kuraklık sınıflarını belirlemek için kullanılır. Efektif kuraklık indeksi değerlerine göre kuraklık sınıfları Çizelge 2' de gösterilmiştir(Byun ve Wilhite, 1999).

Çizelge 2.EKİ değerine göre kuraklık sınıfları

\begin{tabular}{cc}
\multicolumn{2}{c}{ Table 2. Drought classes by EDI values } \\
\hline Kuraklık Sinıfları & İndeks Değeri \\
\hline Çok Şiddetli & $\leq(-2)$ \\
Şiddetli Kuraklık & $(-1.99)-(-1.5)$ \\
Orta Şiddetli & $(-1.49)-(-1)$ \\
Normal & $(-0.99)-(0.99)$ \\
\hline
\end{tabular}

\section{BULGULAR (RESULTS)}

Kuraklık niceliklerinin değerlendirilmesi için bu terimlerin ifade edilmesi gerekmektedir. Kuraklık ile ilgili nicelikler; süre (kuraklık süresi (S)), genlik (toplam indeks değerleri $(G)$ ), şiddet (indeks değerinin tanımlandığı sınıf) ve geri dönüş süresi (kuraklık başlangıcı ile bitişi arasında süre (L)) şeklindedir. EKİ değeri 0'ın altına düştüğü andan itibaren kuraklık başlamış olmaz. Kuraklık olayının başlayabilmesi için EKİ'nin -1 değerinin altına düşmüş olması gerekmektedir. Kuraklığın sonlandığını anlamak içinde EKİ değerinin 0'ın üzerine çıkması gerekmektedir. Buradaki süre kuraklığın başladığı ve bittiği zaman arasındaki zaman dilimini, genlik EKİ değerlerinin toplamını, şiddet ise kuraklığın sınıfını yani EKİ değerinin en düşük değerinin işaret ettiği büyüklüğü belirtmektedir (Çizelge 2., Şekil 2). Bu başlık altında analizi yapılan istasyonlar ayrı ayrı ve zamansal olarak yorumlanmıştır.

Özet tablosu Çizelge 3'tegösterilen analize göre; 20 çok şiddetli kuraklık, 49 şiddetli kuraklık ve 85 orta şiddetli kuraklık olmak üzere toplamda 154 kuraklık olayı tespit edilmiştir. Kuraklık olayı sınıflarına göre ayrı ayrı değerlendirilmiştir.

Çok şiddetli kuraklık sınıfında ortalama kuraklık olayı sayısı 2,5, ortalama kuraklık süresi 35,62 ay, ortalama genliği 55,44'tür. Mardin istasyonunda çok şiddetli kuraklık olayı tespit edilememiştir. Bu sinıfta en fazla kuraklık olayı sayısı Adıyaman, Diyarbakır, Gaziantep istasyonunda tespit edilmiştir. En büyük toplam süreye sahip istasyon ise Diyarbakır istasyonudur. Ayrıca bu istasyon 114,05 değeri ile de en büyük toplam genliğe sahiptir.

Şiddetli kuraklık olaylarının en fazla tespit edildiği istasyon Gaziantep'tir. Bu istasyonda 12 şiddetli kuraklık olayı tespit edilmiştir. Toplam süresi 80 ay, toplam genliği 96,24'tür. Bu sınıfta en büyük toplam kuraklık süresine Siirt istasyonu sahiptir. Bu istasyonun toplam genliği ise 129,31'tir. En büyük toplam genliğe bu istasyon sahiptir. Bu kuraklık sınıfında kuraklık olayı sayısının ortalama değeri 6,13, istasyon başına ortalama süresi 68,13 ay ve ortalama genliği ise $80,81^{\prime}$ dir. Mardin istasyonu en az sayıda şiddetli kuraklık olayının görüldüğü istasyondur. Yine en az kuraklık süresine sahip olan istasyondur.

Orta şiddetli kuraklık sınıfında istasyon başına ortalama kuraklık sayısı 10,63, ortalama kuraklık süresi 50,25 ay ve ortalama genlik 43,72'dir. Bu sınıfta en fazla kuraklık olayı Diyarbakır istasyonunda en az kuraklık olayı Mardin istasyonunda tespit edilmiştir. Ayrıca bu sınıfın en fazla toplam kuraklık süresine Kilis istasyonu sahiptir. 
Çizelge 3. EKİ hesap yöntemi ile aylık olarak tespit edilen kuraklık bilgileri Table 3. Information of Droughts Identified by EDI

\begin{tabular}{lcccccc} 
& \multicolumn{5}{c}{ Çok Şiddetli Kuraklı } & \multicolumn{3}{c}{ Şiddetli Kuraklık } \\
\cline { 2 - 8 } \multicolumn{1}{c}{ İstasyon } & Olay Adedi & Süresi (ay) & Genliği & Olay Adedi & Süresi (ay) & Genliği \\
\hline 1) Adıyaman & 4 & 38 & 63,36 & 7 & 95 & 104,64 \\
2) Batman & 2 & 34 & 37,00 & 4 & 73 & 88,30 \\
3) Diyarbakır & 4 & 64 & 114,05 & 6 & 49 & 56,20 \\
4) Gaziantep & 4 & 47 & 78,91 & 12 & 80 & 96,24 \\
5) Kilis & 1 & 14 & 23,92 & 7 & 58 & 64,03 \\
6) Mardin & 0 & 0 & 0,00 & 2 & 33 & 52,50 \\
7) Siirt & 1 & 37 & 50,36 & 6 & 103 & 129,31 \\
8) Şanlıurfa & 4 & 51 & 75,94 & 5 & 54 & 55,25 \\
\hline \multicolumn{1}{c}{ Ortalama } & 2,50 & 35,63 & 55,44 & 6,13 & 68,13 & 80,81 \\
\hline
\end{tabular}

\begin{tabular}{lrrrrrr}
\cline { 2 - 7 } \multicolumn{1}{c}{ İstasyon } & \multicolumn{3}{c}{ Orta Şiddetli Kuraklık } & \multicolumn{3}{c}{ Toplam } \\
\cline { 2 - 7 } Olay Adedi & Süresi (ay) & Genliği & Olay Adedi & Süresi (ay) & Genliği \\
\hline 1) Adıyaman & 11 & 67 & 59,17 & 22 & 200 & 227,17 \\
2) Batman & 9 & 34 & 27,48 & 15 & 141 & 152,78 \\
3) Diyarbakır & 14 & 46 & 42,75 & 24 & 159 & 213,00 \\
4) Gaziantep & 9 & 52 & 41,74 & 25 & 179 & 216,89 \\
5) Kilis & 12 & 71 & 65,00 & 20 & 143 & 152,95 \\
6) Mardin & 7 & 34 & 32,31 & 9 & 67 & 84,81 \\
7) Siirt & 11 & 54 & 41,36 & 18 & 194 & 221,03 \\
8) Şanllurfa & 12 & 44 & 39,94 & 21 & 149 & 171,13 \\
\hline \multicolumn{1}{c}{ Ortalama } & 10,63 & 50,25 & 43,72 & 19,25 & 154,00 & 179,97 \\
\hline
\end{tabular}

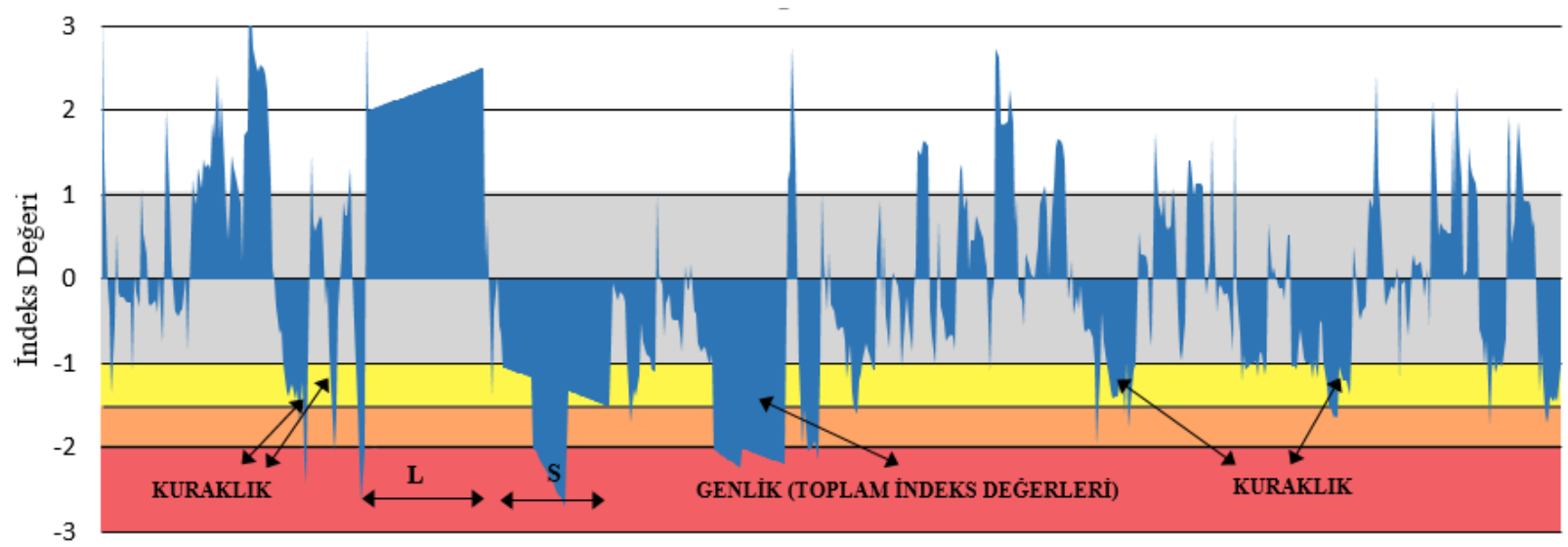

Şekil 2. Kuraklık ile ilgili nicelikler Figure 2. Quantities of drought

Çizelge 4'te ise kuraklıkların zamansal dağılımı gösterilmiştir. Çizelgede en fazla kuraklık olayının 1970-1979 yılları arasında yaşandığı görülmektedir. Ayrıca bu zaman periyodunda en fazla çok şiddetli kuraklık olayı ve orta şiddetli kuraklık olayı tespit edilmiştir. Şiddetli kuraklıkların en çok tespit edildiği zaman periyodu ise 1980-1989 ve 1990-1999 yıllarıdır. 1960-1969 dönemi ise kuraklık olaylarının en az tespit edildiği dönem olarak belirlenmiştir. 
Çizelge 4. EKİ yöntemi ile analizi yapılan kuraklık olaylarının sınıflara göre zamansal dağılımı Table 4. Temporal distribution of drought events by classes identified by EDI

\begin{tabular}{lcccccccccc}
\hline & \multicolumn{3}{c}{ Table 4. Temporal distribution of drought events by classes identified by EDI } \\
\hline \multicolumn{1}{c}{ İstasyon } & ÇŞK & ŞK & OŞK & ÇŞK & ŞK & OŞK & ÇŞK & ŞK & OŞK \\
\hline 1) Adiyaman & 0 & 0 & 2 & 3 & 1 & 3 & 1 & 1 & 1 \\
2) Batman & 0 & 0 & 1 & 1 & 1 & 3 & 0 & 1 & 1 \\
3) Diyarbakır & 0 & 2 & 2 & 2 & 1 & 3 & 0 & 3 & 2 \\
4) Gaziantep & 0 & 3 & 1 & 2 & 3 & 1 & 1 & 0 & 3 \\
5) Kilis & 0 & 0 & 2 & 0 & 1 & 4 & 0 & 2 & 1 \\
6) Mardin & 0 & 0 & 0 & 0 & 0 & 2 & 0 & 1 & 0 \\
7) Siirt & 0 & 1 & 2 & 1 & 1 & 2 & 0 & 2 & 2 \\
8) Şanliurfa & 0 & 0 & 2 & 2 & 1 & 3 & 0 & 0 & 3 \\
\hline \multicolumn{1}{c}{ Ara toplam } & 0 & 6 & 12 & 11 & 9 & 21 & 2 & 10 & 13 \\
\hline \multicolumn{1}{c}{ Genel toplam } & & 18 & & & 41 & & & 25 & \\
\hline
\end{tabular}

\begin{tabular}{|c|c|c|c|c|c|c|c|c|c|c|}
\hline & \multicolumn{3}{|c|}{ 1990-1999 } & \multicolumn{3}{|c|}{$2000-2009$} & \multicolumn{3}{|c|}{ 2010-2016 } & \multirow[b]{2}{*}{ TOPLAM } \\
\hline İstasyon & ÇŞK & ŞK & OŞK & ÇŞK & ŞK & OŞK & ÇŞK & ŞK & OŞK & \\
\hline 1) Adiyaman & 0 & 2 & 3 & 0 & 1 & 1 & 0 & 2 & 1 & 22 \\
\hline 2) Batman & 0 & 1 & 2 & 1 & 0 & 1 & 0 & 1 & 1 & 15 \\
\hline 3) Diyarbakır & 1 & 0 & 4 & 1 & 0 & 1 & 0 & 0 & 2 & 24 \\
\hline 4) Gaziantep & 0 & 2 & 1 & 0 & 2 & 3 & 1 & 2 & 0 & 25 \\
\hline 5) Kilis & 0 & 2 & 1 & 0 & 2 & 3 & 1 & 1 & 0 & 20 \\
\hline 6) Mardin & 0 & 0 & 3 & 0 & 1 & 1 & 0 & 0 & 1 & 9 \\
\hline 7) Siirt & 0 & 1 & 2 & 0 & 1 & 1 & 0 & 0 & 2 & 18 \\
\hline 8) Şanlıurfa & 0 & 2 & 2 & 1 & 0 & 2 & 1 & 2 & 0 & 21 \\
\hline Ara toplam & 1 & 10 & 18 & 3 & 7 & 13 & 3 & 8 & 7 & \multirow{2}{*}{154} \\
\hline Genel toplam & & 29 & & & 23 & & & 18 & & \\
\hline
\end{tabular}

*ÇŞK; Çok şiddetli kuraklık, ŞK; Şiddetli kuraklık, OŞK; Orta şiddetli kuraklık

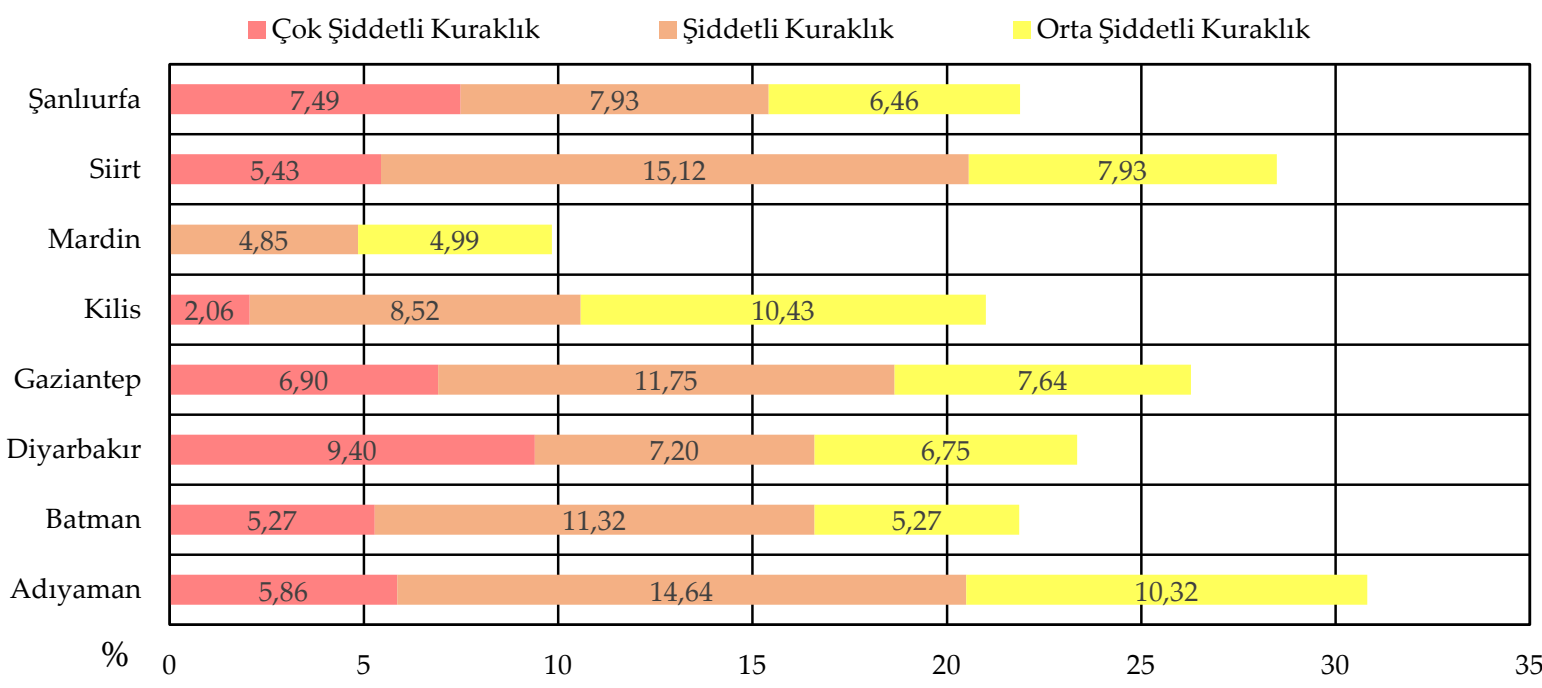

Şekil 3. Kuraklık sınıflarının mekânsal dağılımı

Figure 3. Spatial distribution of droughts 
Toplam kuraklıkların en fazla tespit edildiği istasyon Gaziantep, en az tespit edildiği istasyon ise Mardin'dir. Kuraklıkların olay bazlı yüzdeleri ise Şekil 3'te gösterilmiştir. Bu yüzdeler istasyonlarda tespit edilen kuraklıkla geçen sürenin analiz edilen toplam süreye bölümü şeklinde hesaplanmıştır. Örneğin; istasyondan alınan aylık toplam yağış verisi 400 ay ve toplam 40 ay çok şiddetli kuraklık olayı belirlenmiş olsun. Hesaplaması 40/400* $100=\% 10$ şeklinde olur.

Olay bazlı kuraklıklarda orta şiddetli kuraklık sınıfında en yüksek yüzdesel zaman Kilis $(\% 10,43)$ istasyonunda, en düşük yüzdesel zaman ise Mardin $(\% 4,99)$ istasyonunda tespit edilmiştir. Şekil 3’te gösterildiği gibi şiddetli kuraklık sınıfında en yüksek yüzde Siirt $(\% 15,12)$ istasyonunda, en düşük yüzde Mardin $(\% 4,85)$ istasyonunda bulunmaktadır. Diyarbakır istasyonu çok şiddetli kuraklık sınıfında en yüksek yüzdeye sahiptir. Mardin istasyonunda çok şiddetli kuraklık olayı tespit edilememiştir. Ayrıca kuraklıkla geçen toplam yüzdesel zaman olarak en büyük değerin tespit edildiği istasyon Adıyaman (\%30,82), en küçük değerin tespit edildiği istasyon ise Mardin $(\% 9,84)^{\prime}$ dir.

\section{SONUÇLAR (CONCLUSIONS)}

Yapılan analiz sonucunda çarpıcı olarak Mardin istasyonunun diğer istasyonlara göre en az kuraklık yaşanan il olduğu tespit edilmiştir. Kuraklık olaylarının genliği ve süresi bakımından en fazla etkili olduğu istasyonlar Adıyaman, Siirt ve Gaziantep olarak bulunmuştur. Olay bazlı değerlendirmede ise kuraklık olayları en fazla Adıyaman istasyonunu etkilemiştir. Bölgede kuraklık olayları 1970-1979 periyodunda diğer dönemlere göre daha fazla yaşanmıştır. Ayrıca bölgedeki tüm zamanların \%19'unda kuraklık olaylarının baş gösterdiği tespit edilmiştir.

\section{TEŞEKKÜR ve BILLDİRIM (ACKNOWLEDGEMENT)}

Bu çalışma; yazarlardan Türker Tuğrul'un Yüksek Lisans Tezinden yararlanılarak hazırlanmıştır. Yazarlar, Meteoroloji Genel Müdürlüğü'ne sağlanan veri için teşekkür eder.

\section{KAYNAKLAR(REFERENCES)}

Byun, H. R. ve Wilhite, D. A., 1999, Objective quantification of drought severity and duration, Journal of Climate, 12 (9), 2747-2756.

Çelik, M., Kopar, İ. ve Bayram, H., 2018, Doğu Anadolu Bölgesi'nin Mevsimlik Kuraklık Analizi, Atatürk Üniversitesi Sosyal Bilimler Enstitüsü Dergisi, 22 (3), 1741-1761.

Doğan, S., 2013, Konya Kapalı Havzası Kuraklık Karakterizasyonunun Zamansal-Konumsal Analizi, Doktora Tezi, Selçuk Üniversitesi Fen Bilimleri Enstitüsü, Konya, 123.

Hinıs, M. A., 2013, Hydrometeorological Drought Analysis in Aksaray by Aggregate Drought Index, Journal of the Faculty of Engineering and Architecture of Gazi University, 28 (4), 711-721.

Lee, B. R., Oh, S. B. ve Byun, H. R., 2015, The characteristics of drought occurrence in North Korea and its comparison with drought in South Korea, Theoretical and Applied Climatology, 121 (1-2), 199209.

Lee, S. M., Byun, H. R. ve Tanaka, H. L., 2012, Spatiotemporal Characteristics of Drought Occurrences over Japan, Journal of Applied Meteorology and Climatology, 51 (6), 1087-1098.

Palmer, W. C., 1965, Meteorological Drought, US Department of Commerce, 45, 40-55.

Tsakiris, G., Pangalou, D. ve Vangelis, H., 2007, Regional drought assessment based on the Reconnaissance Drought Index (RDI), Water Resources Management, 21 (5), 821-833. 
Tuğrul, T., 2017, Güneydoğu Anadolu Projesi İllerinin Kuraklık Analizinin Günlük ve Aylık Efektif Kuraklık İndeksi Kullanılarak Karşılaştırılması, Yüksek Lisans Tezi, Selçuk Üniversitesi Fen Bilimleri Enstitüsü, Konya, 98. 